Wegener's granulomatosis is a rare disease (10 per 1000000 new cases pe year), etiologically connected with necrotizing vasculitis of small to medium-size vessels. The disease occurs predominantly in the upper respiratory tract, lungs and kidneys, but any organ may be affected during the course of the illness. It may be difficult to diagnose, especially when c-ACNA antibodies (serologic symptom of Wegener's granulomatosis) are undetectable and chest $X$-ray is normal. Early diagnosis is crucial for treatment results. Untreated disease may lead to death. Cyclophosphamide used simultaneously with prednisone is the treatment of choice as the first line procedure. Resistance to standard systemic treatment may be a significant problem. New drugs (rituximab, infliximab) are still under clinical investigation, with promising results. Very limited data concerning effectiveness of radiation therapy exist. We present a report of a female patient with solitary form of Wegener's granulomatosis located in the facial region, who underwent successful radiation therapy with a complete response.

Key words: Wegener's granulomatosis, radiotherapy, treatment, head and neck.

\section{Low dose radiotherapy as an effective treatment in a patient with solitary Wegener's granulomatosis resistant to systemic treatment - case report}

\author{
Andrzej Wygoda', Tomasz Rutkowski ${ }^{1}$, Krzysztof Składowski ${ }^{1}$, \\ Beata Hejduk ${ }^{2}$
}

1) Radiotherapy Clinic, Maria Sklodowska-Curie Memorial Cancer Centre and Institute of Oncology, Branch Gliwice

2Department of Radiology, Maria Sklodowska-Curie Memorial Cancer Centre and Institute of Oncology, Branch Gliwice

\section{Introduction}

Wegener's granulomatosis is a rare disease, etiologically connected with necrotizing vasculitis of small to medium-size vessels [1-3]. The Scottish otolaryngologist Peter McBride in 1897 and the German pathologist Heinz Karl Ernst Klinger in 1931 were the first physicians to describe this disease. However, the full picture was presented by the German pathologist, Friedrich Wegener, who systematized all the most important symptoms in papers presented in 1936 and 1939. In 1954 Goodman and Chung characterized Wegener's granulomatosis with 'Wegener's triad': 1) necrotizing granulomatous inflammation of upper and/or lower respiratory tract, 2) systemic or focal necrotizing vasculitis involving arteries and veins, and 3) focal segmental necrotizing crescentic glomerulonephritis [4]. According to the routinely used Chapel Hill system, it is classified as one of the small vessel vasculitides.

There are generally no more than 10 per 1000000 new cases per year, with slight prevalence in men. The etiology is still unknown. Genetic predisposition, environmental factors and some drugs are suggested, but infectious factors are the most likely; about $70 \%$ of patients are carriers of Staphylococcus aureus [5]. Also the roles of immune disorders and induced inflammatory processes (autoimmune diseases) are emphasized with monocyte and then granulocyte activation and accumulation in blood vessels. Stimulated endothelial cells activate the coagulation cascade and enzymes secreted from neutrophil granulations lead to small and medium-size vessel destruction and necrosis. Serologic symptom of Wegener's granulomatosis are ANCA antibodies (antineutrophil cytoplasmic antibodies) present in about 90\% of patients and directed against cytoplasmic granulations' neutrophil granulocyte proteins (called c-ANCA) [3, 4].

The disease occurs predominantly in the upper respiratory tract, but also in the lungs and kidneys [3, 6-8]. It should be stressed that any organ may be affected during disease progression $[9,10]$. Wegener's granulomatosis is characterized by a biphasic course: initially the disease is limited to the respiratory tract (upper and lower), then generalization and occurrence of different symptoms resulting from visceral organs' inclusion appear.

Radiotherapy may be used in selected patients with Wegener's granulomatosis refractory to standard treatment [11-13]. It is possible to perform it locally, except for progressive disease, even when it concerns critical organs or is located in their close proximity. Only a few cases treated with radiotherapy have been published in the literature. A case report of a female patient with 
solitary form of Wegener's granulomatosis located in the facial region, who underwent radiation therapy with a complete response, is presented.

\section{Case report}

A 72-year-old woman, in good general performance status, with 4-year symptoms of a slowly growing tumor located at the base of the nose, is presented. The first symptom of disease was a small tubercle located at the base of the nose, near to the internal angle of the right eye, which occurred in January 2003. The patient was initially diagnosed by an ophthalmologist in Rzeszow, Poland, and computed tomography (CT) was ordered. It was performed in May 20, 2003 and it revealed: "Within the sclerotic ethmoid sinus, osteolytic defect with diameter $2 \mathrm{~cm}$ and Hounsfield density 37 is present, filled by soft-tissue mass. Penetration to frontal sinus and right orbit with destruction of its medial wall is observed but without infiltration of intraorbital structures".

A representative sample for histopathology examination was taken and showed: "Abundant inflammatory infiltration composed of plasmatic and lymphocytic cells, epithelial granulomas with caseation necrosis, tuberculous like, focally pyonecrosis and squamous cell metaplasia within surface" (Department of Pathology, Rzeszow). Based on this, the decision to leave the patient in regular follow-up was taken.

One month later control CT showed stable disease, with suggestion of sarcoidosis and tuberculosis as well as the possibility of Wegener's granulomatosis. Chest X-ray and abdominal cavity ultrasonography excluded the presence of other pathologies. All blood tests (morphology, liver and renal parameters) and urinalysis were in the normal ranges, so follow-up examinations were suggested.

The next CT, performed on September 13, 2003 revealed: "At the right base of nose, soft tissue mass with size $3.1 \times 2.9 \mathrm{~cm}$, non-enhancing significantly after contrast injection, is observed. This pathologic structure brings skin in frontal region into relief, penetrates into right orbit with pres- sure on its structure, resulting in exophthalmos. Tumor is located in non-formed right frontal sinus. It causes massive destruction of right frontal bone, nasal bones, especially right, laminae of the ethmoid bone. Tumor does not penetrate into anterior cranial fossa. Destruction of nasal conchae (upper and middle), nasal septum and medial walls of both maxillary sinuses causing communication with nasal cavity is present. Progression of disease".

As a consequence of disease progression, verification of histopathology specimens was performed in the Department of Pathology, Cancer Center and Institute of Oncology in Warsaw (October 2003). A diagnosis of Wegener's granulomatosis was ascertained. Immunosuppression therapy was started: between October 2003 and March 2004 therapy with cyclophosphamide and prednisone was applied, and then therapy based on methotrexate and prednisone was continued to January 2005. Partial regression with long lasting (more than two years) stagnation of tumor size was observed.

In June 2007 the patient reported the regrowth of the tumor. For this, radiotherapy was offered and the patient was directed to the Cancer Center and Institute of Oncology, Gliwice Branch.

The first visit and the examination in the First Department of Radiation Oncology of the Institute took place on September 21, 2007. Frontal headache and excessive right eye tear secretion were the main complaints of the patient.

During physical examination a smooth, well-contoured tumor located at the right base of the nose and near the internal angle of the right eye with size $5 \times 4 \mathrm{~cm}$ (measured with skin, skin not infiltrated) was described. The tumor caused a slight right exophthalmos, but without eyeball movement limitation, diplopia or vision defects. CT performed in our institute was consistent with the previous one, but progression to $3.4 \mathrm{~cm}$ in the greatest dimension was observed (Figs. 1A, 1B).

Radiotherapy was performed in November, 12-29, 2007 in the First Department of Radiation Oncology. The treatment was planned with the intensity modulated radiotherapy (IMRT)
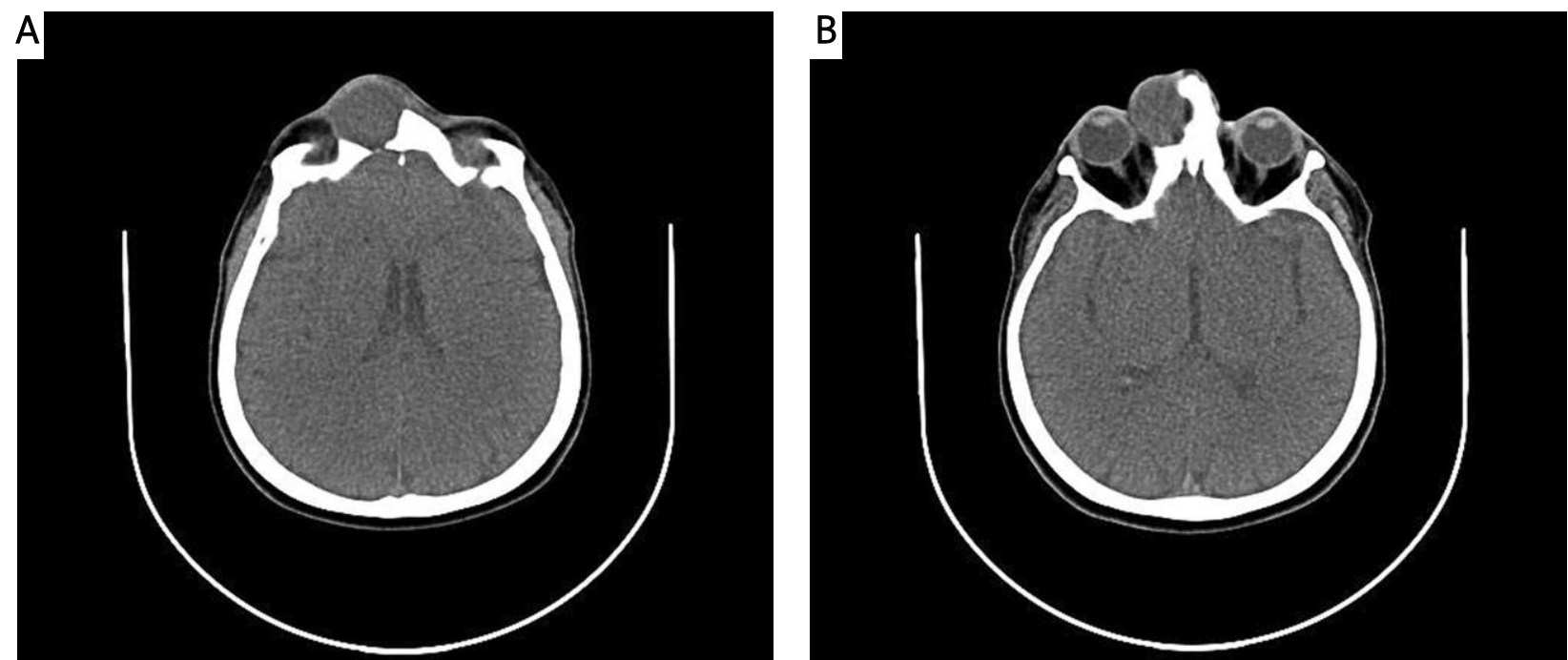

Fig. 1. Computed tomography showed well-controlled tumor located at the right base of the nose and near the internal angle of the right eye 


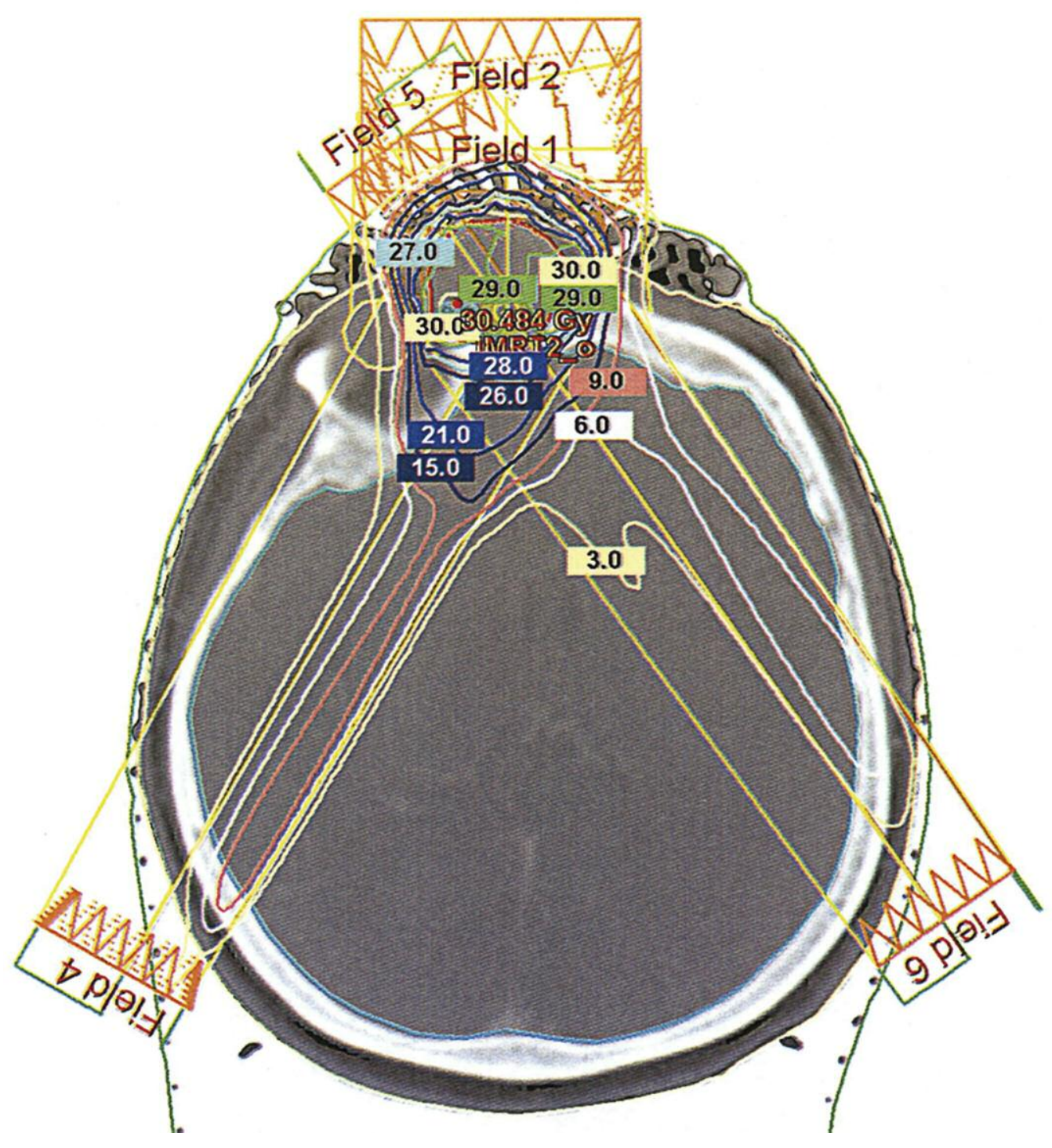

Fig. 2. The arrangement of the irradiation fields with isodose plan

technique. The arrangement of the irradiation fields is presented in Fig. 2. Because of close proximity to the right eyeball and lens, a total radiation dose of 30 Gy conventionally fractionated (2 Gy) was prescribed. Therefore the maximal radiation dose within the right lens did not exceed 5 Gy. No acute effects were observed; tolerance of treatment was very good. The left lens received a radiation dose insignificant for late complications.

Routine follow-up has been performed since the end of treatment in our center. No regression was observed during the first visit, two months after radiotherapy. However, slow, but gradual shrinkage progressed, at first as flattening of the tumor and next as decrease of its dimensions. The regression process lasted 12 months, to March 2009, when complete clinical response was achieved. To ascertain radiological remission, in June 29, 2009, computerized tomography was done - "At present CT no previously described tumor is observed. In its bed only scarring and loss of tissue with- out contrast enhancement is present. Also partial loss in nasal and frontal bones is seen. Part of nasal septum, nasal conchae and middle walls of maxillary sinuses are not visualized" (Figs. 3A, 3B).

The eye examination, performed 3 years after the end of radiotherapy, showed no radiation complications within the organ of vision. Also acuity of vision was still in the normal range.

The last examination was performed in March 2011 and no symptoms of relapse were observed.

\section{Discussion}

Because of its rarity, Wegener's granulomatosis may be difficult to diagnose, especially when c-ACNA antibodies are undetectable and chest X-ray is normal. Early diagnosis is crucial for treatment results. Untreated or improperly treated Wegener's granulomatosis may lead to death in a short time because of renal insufficiency (caused by glomerulonephritis) or massive bleeding into lung alveoli. 

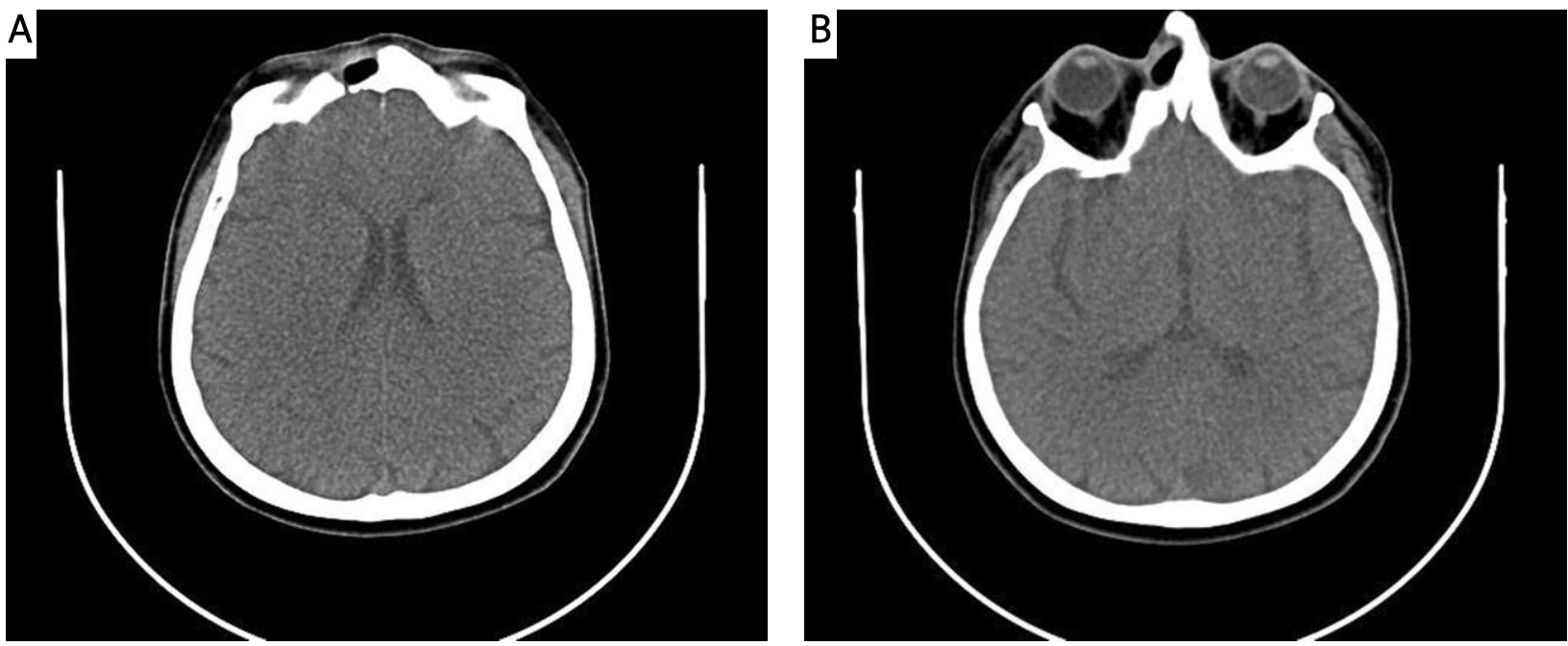

Fig. 3. Control computed tomography showing complete tumor regression (18 months after the end of radiotherapy)

Cyclophosphamide concomitantly with prednisone is the treatment of choice as the first line procedure [2-4, 8, 11, 12, 14-17]. In the remission phase or in patients with stable disease, azathioprine, methotrexate and glucocorticoids are routinely used.

Patients with disease limited to the upper respiratory tract, especially to paranasal sinuses, may be left untreated, but frequent and precise follow-up is required. Resistance to standard systemic treatment may be a significant problem. New drugs are still under clinical investigations - rituximab (chimeric mouse-human monoclonal antibody, selectively binding with membrane cell antigen CD20) and infliximab (chimeric human-mouse monoclonal antibody class IgG1, binding with tumor necrosis factor $\alpha$ ) - but with promising results $[9,18]$. Others, such as etanercept (recombinant receptor protein), showed no effectiveness and even the possibility of induction of solid malignancies was documented [8, 19].

Radiation therapy should be considered in all patients with solitary Wegener's granulomatosis refractory to standard treatment. Very limited data concerning radiation therapy results have been published in the literature so far, but case reports showed a significant response rate $[11,13]$. The routinely used radiation dose ranges between 40 and 50 Gy with conventional fractionation. So far, no lowest, but effective total dose has been established in the treatment of this disease. Our observations suggest the possibility of total dose reduction, which may be crucial, especially when the disease is located in close proximity to critical organs.

In conelusion, the result of our treatment at 3-year follow-up confirms high effectiveness of radiation therapy used in treatment of limited, solitary forms of Wegener's granulomatosis. Escalation of the radiation dose is not necessary, especially when the disease adjoins critical organs.

\section{References}

1. Leavitt RY, Fauci AS, Bloch DA, et al. The American College of Rheumatology 1990 criteria for the classification of Wegener's granulomatosis. Arthritis Rheum 1990; 33: 1101-7.
2. Leavitt RY, Fauci AS. Wegener's granulomatosis. Curr Opin Rheumatol 1991; 3: 8-14.

3. Tarabishy AB, Schulte M, Papaliodis GN, Hoffman GS. Wegener's granulomatosis: clinical manifestations, differential diagnosis and management of ocular and systemic disease. Surv Ophthalmol 2010; 55: 429-44.

4. Yi ES, Colby TV. Wegener's granulomatosis. Semin Diagn Pathol 2001; 18: 34-46.

5. Wiatr E, Gawryluk D. Nowe aspekty patogenezy ziarniniakowatości Wegenera. Pneumol Alergol Pol 2002; 70: 326-33.

6. Pitsch T, Grzanka A, Legaszewski T, Rogala B. Ziarniniakowatość Wegenera maskowana objawami przewlekłego alergicznego nieżytu nosa. Alergia Astma Immunologia 2004; 9: 209-212.

7. Zalesska-Kręcicka M, Jankowska A, Morawska-Kochman M, Kręcicki T. Objawy laryngologiczne w ziarniniakowatości Wegenera. Otolaryngologia 2004; 3: 162-5.

8. Fuchs HA, Tanner SB. Granulomatous disorders of the nose and paranasal sinuses. Curr Opin Otolaryngol Head Neck Surg 2009; 17: 23-7.

9. Shunmugam M, Morley AM, Graham E, D'Cruz D, O'Sullivan E, Malhotra R. Primary Wegener's granulomatosis of the orbital apex with initial optic nerve infiltration. Orbit 2011; 30: 24-6.

10. Leavitt RY, Fauci AS. Less common manifestations and presentations of Wegener's granulomatosis. Curr Opin Rheumatol 1992; 4: 16-22.

11. Eagleton LE, Rosher RB, Hawe A, Bilinsky RT. Radiation therapy and mechanical dilation of endobronchial obstruction secondary to Wegener's granulomatosis. Chest 1979; 76: 609-10.

12. Burlacoff SG, Wong FS. Wegener's granulomatosis. The great masquerade: a clinical presentation and literature review. J Otolaryngol 1993; 22: 94-105.

13. Ziółkowska E, Pietrusińska E, Biedka E, Makarewicz R. Efekt radioterapii u chorego na ziarniniaka Wegenera - opis przypadku. Wspolczesna Onkol 2008; 12: 406-9.

14. Rottem M, Fauci AS, Hallahan CW, Kerr GS, Lebovics R, Leavitt RY, Hoffman GS. Wegener granulomatosis in children and adolescents: clinical presentation and outcome. J Pediatr 1993; 122: 26-31.

15. Hoffman GS, Leavitt RY, Kerr GS, Fauci AS. The treatment of Wegener's granulomatosis with glucocorticoids and methotrexate. Arthritis Rheum 1992; 35: 1322-9.

16. Hoffman GS, Kerr GS, Leavitt RY, Hallahan CW, Lebovics RS, Travis WD, Rottem M, Fauci AS. Wegener granulomatosis: an analysis of 158 patients. Ann Intern Med 1992; 116: 488-98.

17. Hoffman GS, Leavitt RY, Fleisher TA, Minor JR, Fauci AS. Treatment of Wegener's granulomatosis with intermittent high-dose intravenous cyclophosphamide. Am J Med 1990; 89: 403-10.

18. Kontkanen M, Paimela L, Kaarniranta K. Regression of necrotizing scleritis in Wegener's granulomatosis after ifliximab treatment. Acta Ophthalm 2010; 88: e96-7. 
19. Silva F, Seo P, Schroeder DR, et al. Solid malignancies among patients with Wegener's granulomatosis treated with etanercept: long-term follow-up of a multicenter longitudinal cohort. Arthritis Rheum 2011; 63: 2495-503.

\section{Address for correspondence}

dr n. med. Andrzej Wygoda

I Radiotherapy Clinic

Maria Sklodowska-Curie Memorial Cancer Centre

and Institute of Oncology, Branch Gliwice

Wybrzeże Armii Krajowej 15

44-101 Gliwice, Poland

e-mail: awygoda@poczta.onet.pl

Submitted: 26.06.2011

Accepted: $\quad$ 18.01.2012 